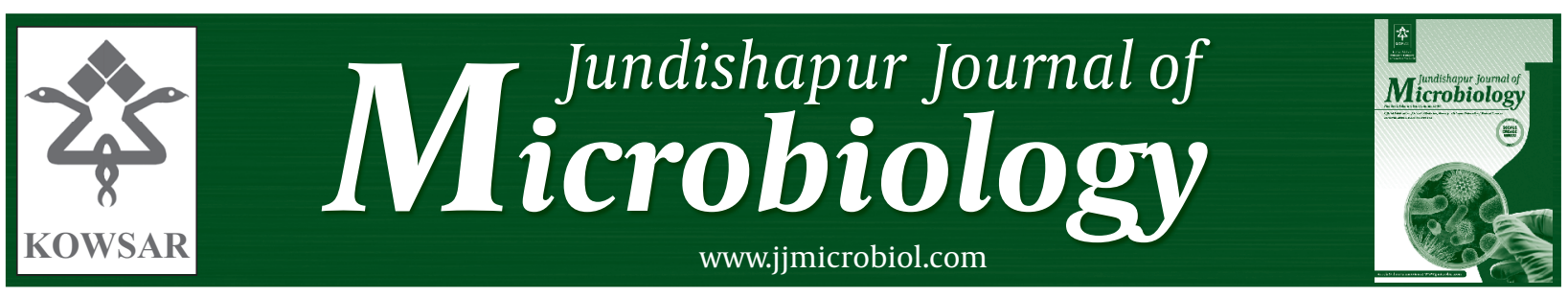

\title{
Molecular Tools in Medical Mycology; Where We Are!
}

\author{
Hamid Badali ${ }^{1^{*}}$, Mojtaba Nabili ${ }^{1}$ \\ ${ }^{1}$ Department of Medical Mycology and Parasitology/Invasive Fungal Research Centre (IFRC), School of Medicine Mazandaran University of Medical Sci- \\ ences, Sari, IR Iran
}

\section{A R T I C L E I N F O}

Article type:

Editorial

Article history:

Received: 10 Oct 2012

Revised: 11 Oct 2012

Accepted: 14 Oct 2012

Keywords:

Molecular Biology

Medical Mycology

\section{Introduction}

In the past, diagnostic classification was mainly based on morphological and culture criteria, which sometimes supplemented with physiological information. Unfortunately, some of them are insufficient when a culture is sterile, or they are in slow growing style. In addition, conventional methods often rely on identification of clinical manifestation, isolation and culturing of environmental organisms and laboratory identification based on morphology and biochemical tests, which lead to problems in identification, resulting in incorrect interpretation, diagnosis and ultimately treatment. The latter methods depend on experienced, skilled laboratory staff, the ability of the organism to be cultured, are time consuming, non-quantitative, prone to contamination and error and in the case of medical pathology often delay treatment. Therefore, understanding and the need arose for methods that allow the identification of organisms even though as sterile which can thus not be identified to the species level based on phonotypical point of view, and
-Implication for health policy/practice/research/medical education:

In fact despite a couple of limitations, in the near future molecular tools for the identification of fungal species will no doubt expand rapidly. Fungal DNA with a combination of automated technologies is currently under commercial development for diagnosis.

- Please cite this paper as:

Badali H, Nabili M. Molecular Tools in Medical Mycology; Where We Are! Jundishapur J Microbiol. 2013;6(1):1-3. DOI: 10.5812| jjm.8566

Published by Kowsar Corp, 2013. cc 3.0.

owing to the disappointing performance of culture and serologic based assays, research has - since the early $1990 \mathrm{~s}$ - been focused on molecular approaches to detect the fungal pathogen as early as possible with high sensitivity and specificity.

Although, early studies to evaluate PCR-mediated detection of fungi showed significantly improved sensitivity compared with other diagnostic methods, were performed with different approaches and distinctive objectives, optimize culture assays $(1,2)$ molecular and epidemiological typing and often in nonclinical settings $(3,4)$. Thus, the positive benefits of carrying out highly sensitive DNA detection assays should be taken into accounted. The development of molecular approaches was revolutionized by the discovery of the polymerase chain reaction (PCR) which allows the amplification of a large number of copies of a part of low concentrations of DNA, which is a suitable for either sterile or slow growing fungi. The first PCR assays detected quantities down to $1-20 \mathrm{pg}$ of fungal genomic DNA in vitro (5) which indicated with a

\footnotetext{
${ }^{*}$ Corresponding author: Hamid Badali, Department of Medical Mycology and Parasitology/Invasive Fungal Research Centre(IFRC), School of Medicine, Mazandaran University of Medical Sciences, Sari, P.O. Box: 48175-1665, IR Iran, Tel:+98-9128413720, Fax:+98-1513543248, E-mail: badalii@yahoo.com

DOI: $10.5812 /$ jjm. 8566

(C) 2013 Ahvaz Jundishapur University of Medical Sciences; Published by Kowsar Corp.

This is an Open Access article distributed under the terms of the Creative Commons Attribution License (http://creativecommons.org/licenses/by/3.0), which permits unrestricted use, distribution, and reproduction in any medium, provided the original work is properly cited.
} 
range of different PCR assays (conventional, nested, realtime based) and have been developed, targeting different gene regions (cytochrome p450, heat shock proteins, 18S, $5.8 \mathrm{~S}, 28 \mathrm{~S}$, ITSrDNA). Furthermore, they include a variety of amplicon detection methods, such as gel electrophoresis, hybridization with specific probes (LAMP, RCA), ELISA, restriction fragment length polymorphism (RFLP), Amplified fragment length polymorphism (AFLP) and DNA sequencing.

\section{Polymerase chain reaction (PCR)}

Polymerase chain reaction (PCR)-detection of fungi nucleic acids is increasingly appreciated as being a method of early detection of fungal infection (6). However several manuscripts have been published dealing with the detection of fungal DNA; there has been little standardization in procedures and very few inter-laboratory validation studies. PCR technique can be used as (I) diagnostic; (ii) early diagnosis of fungal infection; (iii) monitoring the pre-emptive antifungal therapy. The development of PCR technology relies on three fundamental steps: I) the selection of a specific target region of DNA/RNA to identify the fungus; II) extraction of DNA/RNA from the environmental sample; III) a method to identify the presence of the target DNA/RNA region in the sample.

\section{Nested PCR}

Nested PCR formats have been widely used for fungal species in an attempt to optimize analytical sensitivity, but the requirement to open reaction tubes means that there is the considerable risk of contamination and the subsequent generation of false-positive results (7).

\section{PCR-ELISA}

PCR-ELISAs have been in use since the late 1980s and have developed into an assay for detecting specific sequences within PCR products, which is useful for detecting and differentiating between multiple targets and screening several samples. It is a capture assay for nucleic acids that mimic enzyme linked immunosorbant assays. In this assay, PCR products hybridized to an immobilized capture probe. The assay thus measures sequences internal to the PCR product and is an inexpensive assay and an alternative to real time PCR. The major advantages of the PCR-ELISA identification system, compared to conventional phenotypic identification methods, were: rapid, fewer amounts of genomic DNA, reproducible, specific DNA probes and automated (8).

\section{Real time PCR}

Real time PCR or quantitive PCR(Q-PCR) technologies allow for rapid and effective post amplification of specific DNA sequences such as ITS rDNA regions for genus and species-specific identification of opportunistic fungi. Q-
PCR is less prone to contamination; along with automated systems for DNA extraction appear to be a significant step towards standardization and improvement of the reliability of the existing PCR assays. Because real-time PCR allows for quantification of the amount of circulating fungal DNA, it may also be used as an indirect parameter of fungal load during monitoring of treatment with antifungal drugs. The monitoring of accumulating amplicon in real-time has been made possible by the labeling of primers, oligonucleotide probes or the amplicon itself with molecules capable of fluorescing. These labels produce a change in signal following direct interaction with the amplicon or hybridization to the amplicon. The signal increases as the amount of amplicon increases after each amplification cycle which obtained based on several approaches such as SYBR Green, FRET and Taq Man technology $(9,10)$.

\section{RFLP}

Restriction fragment length polymorphism (RFLP) is a technique that exploits variations in homologous DNA sequences. It refers to a difference between samples of homologous DNA molecules that come from differing locations of restriction enzyme sites, and to a related laboratory technique by which these segments can be illustrated. In RFLP analysis, by restriction enzymes the DNA samples are broken into pieces and are separated according to their lengths by gel electrophoresis. Although now largely obsolete due to the rise of inexpensive DNA sequencing technologies, RFLP analysis was the first DNA profiling technique inexpensive enough to see widespread application. In addition to genetic fingerprinting, RFLP was an important tool in genome mapping, localization of genes for genetic disorders, determination of risk for disease, and paternity testing (11).

\section{AFLP}

Amplified fragment length polymorphism (AFLP) is a technique based on the detection of genomic restriction fragments by PCR amplification, which can be used with the DNA of any organism. AFLP is one of a series of techniques for phylogenetic studies, plant and animal genetic mapping, and genotyping and is well suited for distinguishing closely related organisms at the species to strain level. The AFLP method relies on selective amplification of restriction fragments from a digest of genomic DNA and has many advantages compared to other marker technologies, including randomly amplified polymorphic DNA, restriction fragment length polymorphism, and microsatellites. AFLP not only has higher reproducibility, resolution, and sensitivity at the whole-genome level than other random amplification techniques but it also has the ability to amplify between 50 and 100 fragments at one time. In addition, no prior sequence information is needed for amplification $(12,13)$. 


\section{DNA Sequencing}

The purpose of sequencing is to determine the order of the nucleotides of a given piece of DNA. Since early 1970s DNA sequencing was developed based on two-dimensional chromatography, following the development of dye-based sequencing methods with automated analysis, gene or nucleotide sequencing has become easier and orders of magnitude faster, it may be used to determine the sequence of individual genes, genetic regions (i.e. clusters of genes or operons) or whole genomes. Sequencing may provide the order of nucleotides in DNA or RNA isolated from organisms or other source of genetic information. The resulting sequences may be used by researchers in molecular biology or genetics to further scientific progress or may be used by medical personnel to make treatment decisions (14).

\section{RCA}

Rolling circle amplification (RCA) was discovered in the 1990s which is based on the rolling replication of short, single stranded DNA circles by certain DNA polymerases under isothermal conditions (15).It is one of a series of the robust and simple techniques for distinguishing closely related organisms, at the species as well as the strain level. The sensitivity of RCA enables precise and reliable distinction and quantification of gene copy numbers and gene expression levels in individual cells. The test can be performed within 2 hours isothermally in a water bath, thermocycler, heating block or microwave oven utilizing specific nucleic-acid sequences in DNA samples. Signals appear within $15 \mathrm{~min}$ after onset of RCA reaction based on real time PCR (Q-PCR). Circularized oligonucleotide (padlock) probes have been demonstrated to be more sensitive for the detection of target sequences than conventional primers, although gel-based detection of RCA still needs some detection optimization. RCA has recently been introduced in a mycological context and the method was successfully applied Candida, Aspergillus, Scedosporium, Trichophyton and Cryptococcus, Fusarium, and Fonsecaea. Time and cost-effectiveness are crucially important for screening and epidemiological studies (16)

\section{Discussion}

Fungal diagnostics have increased dramatically with the introduction of molecular tools, in particular, that of PCR. There are many applications for this technology and the aim now is to produce products that can detect fungal isolates at source without the need for samples to be taken back to the laboratory for processing. Correct identification by mycological procedures remains difficult, due to the high degree of phenotypic similarity. In most cases published in the older literature, the etiological agent may often have been misidentified; how- ever, re-identification down to the species level cannot be performed by molecular methods due to the absence of the original isolates. Advances in automation of many of these processes mean that rapid screening of samples can now be undertaken, and commercialization of detection of fungal pathogens subject to government regulations on fungal disease levels and quarantine are now feasible. PCR technology has many applications in medical mycology and each year the technology is improved and new aspects are considered and tested. The future holds many challenges, but will prove to be an exciting time. Molecular diagnostics are making a huge impact on research in mycology, and in time, its importance will increase in the monitoring, detection, quantification and identification of fungi, leading to better management and control of human disease, and investigation of beneficial fungi.

\section{References}

1. Aufauvre-Brown A, Cohen J, Holden DW. Use of randomly amplified polymorphic DNA markers to distinguish isolates of Aspergillus fumigatus. J Clin Microbiol. 1992;30(11):2991-3.

2. van Belkum A, Quint WG, de Pauw BE, Melchers WJ, Meis JF. Typing of Aspergillus species and Aspergillus fumigatus isolates by interrepeat polymerase chain reaction. J Clin Microbiol. 1993;31(9):2502-5.

3. Birch M, Nolard N, Shankland GS, Denning DW. DNA typing of epidemiologically-related isolates of Aspergillus fumigatus. Epidemiol Infect. 1995;114(1):161-8.

4. Verweij PE, Meis JF, Sarfati J, Hoogkamp-Korstanje JA, Latge JP, Melchers WJ. Genotypic characterization of sequential Aspergillus fumigatus isolates from patients with cystic fibrosis. J Clin Microbiol.1996;34(10):2595-7.

5. Reddy LV, Kumar A, Kurup VP. Specific amplification of Aspergillus fumigatus DNA by polymerase chain reaction. Mol Cell Probes. 1993;7(2):121-6.

6. Chen SC, Halliday CL, Meyer W. A review of nucleic acid-based diagnostic tests for systemic mycoses with an emphasis on polymerase chain reaction-based assays. Med Mycol. 2002;40(4):333-57.

7. Hope WW, Walsh TJ, Denning DW. Laboratory diagnosis of invasive aspergillosis. Lancet Infect Dis. 2005;5(10):609-22.

8. Hinrikson HP, Hurst SF, De Aguirre L, Morrison CJ. Molecular methods for the identification of Aspergillus species. Med Mycol. 2005;43 (Suppl 1):S129-37.

9. Saha BK, Tian B, Bucy RP. Quantitation of HIV-1 by real-time PCR with a unique fluorogenic probe. J Virol Methods. 2001;93(1-2):33-42.

10. Vet JA, Majithia AR, Marras SA, Tyagi S, Dube S, Poiesz BJ, et al. Multiplex detection of four pathogenic retroviruses using molecular beacons. Proc Natl Acad Sci U S A. 1999;96(11):6394-9.

11. Monod M, Bontems O, Zaugg C, Lechenne B, Fratti M, Panizzon R. Fast and reliable PCR/sequencing/RFLP assay for identification of fungi in onychomycoses.J Med Microbiol. 2006;55(Pt 9):1211-6.

12. Badali H, de Hoog GS, Curfs-Breuker I, Klaassen CH, Meis JF. Use of amplified fragment length polymorphism to identify 42 Cladophialophora strains related to cerebral phaeohyphomycosis with in vitro antifungal susceptibility.J Clin Microbiol. 2010;48(7):2350-6.

13. Vos P, Hogers R, Bleeker M, Reijans M, van de Lee T, Hornes M, et al. AFLP: a new technique for DNA fingerprinting. Nucleic Acids Res. 1995;23(21):4407-14.

14. Maxam AM, Gilbert W. A new method for sequencing DNA. Proc Natl Acad Sci U S A. 1977;74(2):560-4.

15. Fire A, Xu SQ. Rolling replication of short DNA circles. Proc Natl Acad Sci US A.1995;92(10):4641-5.

16. Zhou X, Kong F, Sorrell TC, Wang H, Duan Y, Chen SC. Practical method for detection and identification of Candida, Aspergillus, and Scedosporium spp. by use of rolling-circle amplification. $J$ Clin Microbiol. 2008;46(7):2423-7. 